\title{
AGAINST PHENOMENAL EXTERNALISM
}

\author{
ELISABETTA SACCHI \\ Università Vita-Salute San Raffaele \\ sacchi.elisabetta@hsr.it \\ Alberto Voltolini \\ Università degli Studi di Torino \\ alberto.voltolini@unito.it
}

SUMMARY: We maintain that no extant argument in favor of phenomenal externalism $(\mathrm{PE})$ is really convincing. $\mathrm{PE}$ is the thesis that the phenomenal properties of our experiences must be individuated widely insofar as they are constituted by worldly properties. We consider what we take to be the five best arguments for PE. We try to show that none of them really proves what it aims at proving. Unless better arguments in favor of phenomenal externalism show up in the debate, we see no reason to relinquish an idea that seems intuitive and appeals to many cognitive scientists: that phenomenology is narrow, i.e., that phenomenal properties are intrinsic properties of our experiences. This idea grounds the opposite philosophical position, phenomenal internalism (PI).

KEY WORDS: epistemic and phenomenal indistinguishability, phenomenal character, phenomenal nature, phenomenal internalism

RESUMEN: Queremos mostrar que ninguno de los argumentos conocidos a favor del externismo fenoménico (PE) es convincente. $\mathrm{PE}$ es la tesis de que las propiedades fenoménicas de nuestras experiencias se tienen que individuar en modo amplio en la medida en la que están constituidas por propiedades del mundo. Examinamos los que nos parecen los cinco mejores argumentos a favor de PE. Intentamos mostrar que ninguno de ellos puede establecer el resultado deseado. Mientras no aparezcan argumentos mejores en el debate, no tenemos razón para renunciar a una idea que parece intuitiva y atractiva para muchos psicólogos cognitivos: que la fenomenología es estrecha, es decir, que las propiedades fenoménicas son propiedades intrínsecas de nuestras experiencias. Esta idea subyace a la posición filosófica opuesta, el internismo fenoménico (PI).

PALABRAS CLAVE: indistinguibilidad epistémica y fenoménica, carácter fenoménico, naturaleza fenoménica, internismo fenoménico

\section{Some Preliminaries}

To begin with, the most intuitive position as regards the phenomenology of our experiences seems to be that it is narrow. In other words, there intuitively is an individuation of the phenomenal properties of our experiences, like the painfulness of our pains and the reddishness that our present perception of a red tomato shares with certain of our after-images and even with some of our phosphenes, as intrinsic, hence monadic aka non-relational, properties of our experiences, for no worldly properties in the last two cases contribute 
to the constitution of such phenomenal properties. These are the properties that determine the so-called phenomenal character of an experience, its "what it is like". The intuitivity of taking the phenomenology of our experiences to be narrow hinges on the fact that phenomenal properties appear to us, as subjects of those experiences, as intrinsic properties of them. In other words, either we believe by introspection that the "what it is like" of our experiential states is non-relational, or - to put it in phenomenologically vivid terms - we even have a feeling on this concern: phenomenal properties are felt to be non-relational. Moreover, it should be stressed that cognitive sciences seem to go hand in hand with these intuitive considerations. Neuroscientists often claim that phenomenally identical experiences have the same inner causes in physical events happening in the experiencers' brains. This strongly encourages, without of course providing conclusive support in favor of, the idea that the phenomenal properties of such experiences at least supervene on the physical intrinsic properties of such events, hence are narrow as well. ${ }^{1}$

If this is the case, one may think that the correct position to hold on these matters is phenomenal internalism (PI), the claim that what constitutes the phenomenology of our experiences, i.e., our phenomenal properties, must be individuated narrowly, i.e., as intrinsic properties of such experiences, for they are not constituted by worldly properties.

True enough, intuitions, or at least prima facie considerations, by themselves prove nothing. It often happens in philosophy that counterintuitive claims turn out to be theoretically fruitful positions on closer examination. Yet if we do have such intuitions, there must be some good reasons as to why we ought to relinquish them. Thus, the burden of proof is on those who want to dispense with such intuitions to show that they have to be rejected because of their being wrongheaded. Now, phenomenal externalism (PE) is the philosophical position holding the opposite idea that the phenomenology of our experiences is wide, or in other terms, that phenomenal properties must be

${ }^{1}$ Fish (2009, p. 136) thinks that this inference to the best explanation is not justified, for one may provide an alternative explanation of how phenomenal properties may be grounded on cerebral activities. According to such an explanation, such cerebral activities consist in a selective detection of those worldly properties that constitute phenomenal properties (p. 137). Yet this explanation presupposes naive realism (in the variety that Fish endorses), which is precisely one of the positions supporting PE that we will question in what follows. As Fish himself indeed acknowledges (pp. 118, 125), if we ascribed a phenomenal character to a clearly nonrelationally individuated experience, this would plausibly supervene on the cerebral state of the subject entertaining that experience. 
individuated extrinsically, i.e., in terms of the worldly properties our experiences put us in relation with. Accordingly, PE wants to deny the relevance of those intuitions in a theoretical account of the individuation of phenomenal properties. And indeed, in order to neutralize the counterintuitivity of their position, sustainers of $\mathrm{PE}$ are convinced that there are arguments in favor of $\mathrm{PE}$ that manage to nullify the strength of these intuitions, undermining therefore PI as well.

This dialectic notwithstanding, it must be immediately pointed out that it is not easy to isolate within the philosophical literature explicit arguments in support of PE. For in most cases, what one finds are rather arguments in favor of other claims that have PE as one of their consequences. Nevertheless, we think it is possible to individuate some main argumentative lines that are in place, even though not always explicitly, in the works of those who react to phenomenal internalism. ${ }^{2}$

To be sure, in order for them to be non-question begging, such arguments must not assume any claim that implies PE as one of their premises. One such claim is for example wide intentionalism, i.e., the conjoint thesis according to which (i) the phenomenal properties of an experience are identical with (or at least supervene on) the represented properties of the experience, i.e., the worldly properties that allow for such an experience to represent that so and so is the case, and (ii) such properties are wide. ${ }^{3}$ For if one adopts wide intentionalism, then of course PE follows. Yet since intentionalism as such and a fortiori wide intentionalism are controversial theses, it would be better to argue for PE without assuming them. ${ }^{4}$ Therefore, we will confine our attention to what we take to be the best arguments in support of $\mathrm{PE}$ that meet this requirement.

Granted, these arguments are differently structured, for some of them are more refined than others. Yet we will try to show that no such argument really works, naturally by focusing on the more refined ones.

For the purposes of this paper, we will do nothing more. We do not intend either to provide arguments in support of PI, or to defend any particular phenomenal internalist approach. As we said before, since the idea that the phenomenology of our experience is narrow is

${ }^{2}$ Lycan 2001 himself makes an inventory of externalist arguments. In our work, besides considering them, we have added some other arguments that can be reconstructed from what externalists say about related topics.

${ }^{3}$ On intentionalism, cf., e.g., Crane 2001.

${ }^{4}$ An example of this way of arguing in favor of PE is provided by Dretske 1995, chap. 5 . 
rooted in our intuitive grasp of the nature of such a phenomenology that neuroscientific approaches to the mind typically share, showing that the opposite claim constituting PE is ungrounded seems to us to be enough in order to, at least provisionally, keep on sticking to that idea.

\section{Against the Irrelevance of Indistinguishability Argument}

In this section we will discuss an argument in support of PE that comes out of a reply to a somewhat implicit line of reasoning that could be ascribed to a supporter of phenomenal internalism. We are here using Lycan's (2001) label for it. To begin with, a defender of PE may suspect that, pace PI's alleged intuitivity, an implicit argument actually lies behind the phenomenal internalist's idea that the phenomenology of our experiences is narrow. This implicit argument on behalf of PI is the following:

(a) If phenomenal properties were wide, then there would be a relevant sort of Twin-Earth in which the phenomenal character of a twin's mental state is different from the one her Earthling twin enjoys.

(b) Yet if one were transported to that Twin-Earth, one would enjoy a mental state indistinguishable as regards its phenomenal properties from the state one enjoys on Earth.

(c) Hence, the fact that the two mental states are indistinguishable as regards their phenomenal properties counts as a proof of the narrowness of those properties.

To clarify matters, the kind of Twin-Earth that is involved in this implicit argument is not a standard Putnamian Twin-Earth. In the standard Twin-Earth cases, we are presented with a scenario in which two planets differ in some worldly aspect that is relevant as far as certain content-determining items are concerned (natural kind properties, surrounding objects), but the scenario is also one in which the phenomenal properties are assumed not to change with respect to Earthling phenomenal properties. Now, since phenomenal properties in the standard Twin-Earth cases are assumed to be identical across planets, nothing is said as to whether they have to be individuated widely, ${ }^{5}$ that is, in terms of worldly properties that remain constant across the planets, or narrowly, that is, in terms of the same intrinsic

${ }^{5}$ As Tye 1995 wishes. 
properties of the Earthling and of the Twin-Earthling experiences. Yet, the new Twin-Earth hypothetical scenario that is involved in the above implicit argument on behalf of PI allegedly involves a difference in phenomenal properties widely construed; that argument is precisely designed to dismiss that scenario. Yet if this is the case, the defender of PE rebuts, that argument is a non-sequitur. For its conclusion is not warranted, she claims, as a very simple further argument may show. This externalist argument - the irrelevance of indistinguishability argument - therefore works as a reply to the above implicit internalist argument. It is an argument by analogy running as follows:

(1) In a standard Twin-Earth case, the fact that two mental states are indistinguishable does not prove that their intentional properties are narrow.

(2) Thus by analogy, the fact that two experiences are indistinguishable, as actually happens in the new Twin-Earth case, does not prove that their phenomenal properties are narrow.

So, (c) in the previous implicit argument on behalf of PI is false, hence that argument does not hold and PI should be rejected, for it loses its argumentative support. ${ }^{6}$

As we said at the very beginning, we intend to provide here no positive argument in favor of PI. Thus, even if our following criticisms against the externalist's argument were correct, we remain silent on whether the above implicit internalist's argument works. Nevertheless, we hold that the externalist's argument would be sound (hence, the internalist's argument would not work) only if the indistinguishability appealed to in both arguments were a mere epistemic indistinguishability (EInd). This is the inability to tell one experience from another by introspection or reasoning alone, or even more radically the fact that, for all a certain subject knows, her experience could turn out not to be the experience that she takes it to be (it may turn out to be the perception of a different thing or even a hallucination).

Yet, as many people have pointed out, ${ }^{7}$ one must distinguish EInd from phenomenal indistinguishability (PInd), i.e., the inability to distinguish two experiences constitutively depending on their

\footnotetext{
${ }^{6}$ For such an argument, cf. Lycan 2001.

${ }^{7}$ For the distinction between phenomenal indistinguishability and epistemic indistinguishability, cf. Farkas 2006, p. 208. Such notions can also be traced back to Martin; e.g., 1997, 2004, 2006.
} 
having the same phenomenal properties. In other terms, phenomenal indistinguishability is a form of identity: things look identical because their phenomenal look is identical, i.e., they share the same phenomenal properties. In a nutshell, unlike epistemic appearance, phenomenal appearance collapses onto phenomenal reality: phenomenally seeming to be the same is to be the same. Clearly enough, the two notions are distinct: although PInd entails EInd, the converse does not hold, as the cases of inattentional blindness and change blindness clearly show. In such cases, even though one cannot distinguish one of one's experiences from another by appealing to introspection or reflection alone, one nevertheless has a different phenomenal awareness as regards such experiences; phenomenal properties change even if report awareness is unable to detect such a change. ${ }^{8}$ Thus, things epistemically indistinguishable can well be phenomenally distinguishable, hence, phenomenally distinct.

Now, once one draws the distinction between EInd and PInd, the irrelevance of indistinguishability argument of the externalist no longer holds. For, we claim, the externalist's argument mobilizes EInd in (1) yet PInd in (2) (whereas in order to be sound, the above implicit internalist's argument must mobilize the latter notion only). As a consequence, the analogy called upon in (2) does not hold. Even if it may be the case that epistemically indistinguishable mental states are intentionally different (epistemic appearance does not collapse onto intentional reality), it cannot be the case that phenomenally indistinguishable experiences are phenomenally different (phenomenal appearance does collapse onto phenomenal reality).

On behalf of the phenomenal externalist, one may reply as follows. ${ }^{9}$ Pace the phenomenal internalist, the indistinguishability that is appealed to in (2) must be EInd as well. As regards (2), says the advocate of $\mathrm{PE}$, our starting point is that a genuine perception is not knowably distinct (by introspection or reasoning) from a corresponding hallucination; or even more radically, that there is no possibility of realizing that if one moves from Earth to an "empty" Twin-Earth, one passes from entertaining a genuine perception to entertaining a corresponding hallucination. Now, such an indistinguishability gives no reason to infer that the mental states in question have something in common, notably a phenomenal look to be interpreted in terms of

\footnotetext{
${ }^{8}$ To put it in Raftopoulos' 2009 terms. A similar situation holds if one entertains an experience of a certain shade of color; for all one knows by introspection or reflection alone, one could entertain an experience of an imperceptibly different shade. Cf. Farkas 2006, for whom PInd is actually more basic than EInd.

${ }^{9}$ One can find outlines of such a reply in Martin 2006, p. 369.
} 
sameness of phenomenal properties. Hence, the externalist argument goes through.

We disagree on this interpretation of (2). Unlike cases of epistemic indistinguishability, the indistinguishability that (2) calls upon has not to do with an introspective inability to know the relevant fact that makes a difference between the involved items. Such an inability would occur for example in a case in which a subject could not tell whether she is dealing with a historical tale rather than a fictional tale. ${ }^{10}$ Indeed in such a case, once the subject were told the relevant fact (for instance, that the tale is fictional), this knowledge would suffice in order for her overall stance towards the situation to change (for instance, she would no longer use that text as testimony). Yet in the case of (2), the subject's inability to distinguish among her experiences is grounded in the fact that the relevant experiences share the same phenomenal look, hence it is a matter of PInd rather than of EInd. Indeed, even if a hallucinating subject were told that the experience she is now entertaining is hallucinatory, for there exists no concrete entity as a source of that experience, this knowledge would not suffice in order for her overall stance towards that experience to change; for example, she would go on being afraid of what she is (knowingly) hallucinating. The externalist argument therefore gives no credence to the claim that phenomenal properties are wide.

To better see our point, let us focus on proprioceptive sensations. True enough, by introspection or reasoning alone a subject cannot tell whether one's proprioception of a limb is (or has turned into) a hallucinatory proprioception, if the limb is a phantom one. Yet how things really stand in the world, i.e., the fact that there exists no such limb, makes no difference to such a subject, for her being unable to distinguish between the veridical and the hallucinatory proprioception is grounded in the fact that she is still phenomenally aware of the same experience since it goes on having the same phenomenal look. Putting things in another perhaps more traditional way, we can say that, no matter what actually happens in the external world, the seeming to one that one is sensing in a certain way is enough in order for one to sense in that way; once again, the phenomenal appearance of a sensation and its phenomenal reality collapse. ${ }^{11}$ Yet to sense in a certain way is just to entertain a certain "what it is like", i.e., a certain phenomenal character determined by the phenomenal properties of the proprioceptive sensation in question.

${ }^{10}$ To refer to an example explicitly appealed to by Martin 2006, p. 401.

${ }^{11}$ As Martin himself (2006, p. 397) seems to acknowledge. 


\section{Against the Transparency Argument}

The idea that experience is transparent, meant as the idea that introspection reveals that properties apparently of the experience are represented properties, properties of what the experience is about, worldly properties, is often used to support (wide) intentionalism, the aforementioned claim that phenomenal properties depend on represented (wide) properties. ${ }^{12}$ So, on the grounds of what we have said about our decision to consider only independent, non-question begging, arguments in support of $\mathrm{PE}$, one might wonder why we are going to consider an argument relying on transparency as an independent argument in favor of PE. Does not such an argument prove PE via (wide) intentionalism, which, as we said, is an easy yet controversial way to support PE?

Yet, as we shall see, transparency may be used to support PE directly without any mediation of intentionalism. Here indeed is how the transparency argument actually runs:

(1) If experience is transparent, then phenomenal properties have to be identified with the worldly properties the experience is about, hence as wide properties.

(2) Experience is transparent.

(3) Hence, phenomenal properties have to be identified with wide properties. $^{13}$

To be sure, this argument does not raise the problems of the externalist argument we discussed in the previous section. For it is compatible with endorsing PInd: phenomenally indistinguishable experiences mobilize the same phenomenal properties that are, however, if the argument holds, wide properties.

Yet premise (1) of this new argument can be questioned. Suppose one accepts transparency and therefore the idea that properties apparently of the experience are, rather, properties of worldly items (which for intentionalists constitute the representational content of the experience); for instance, the experience of red is the experience of the worldly property of being red. However, this does not yet show that such properties constitute the experience's phenomenal character, hence the phenomenal properties of such an experience. For it still remains possible to claim that the properties in question

${ }^{12}$ Cf., e.g., Tye 1995.

${ }^{13}$ For this argument see Dretske 1995, Tye 1995. 
manifest themselves in the experience (phenomenologically, so to say) to the bearer of the experience by means of certain manners. ${ }^{14}$ Such manners therefore turn out to be properties of the experience itself that constitute its phenomenal character. Basically following Chalmers (2004), we here speak of "manners of manifestation" rather than "modes of presentation", in order to underline the fact that these manners cannot be ranked within the represented properties that constitute the content of the experience, hence not even with properties determining such content, as happens with modes of presentation of represented properties according to their defenders. Unlike modes of presentation of worldly properties (whatever they are: Fregean Sinne, Husserlian Abschattungen or what have you), not only one and the same worldly property may manifest itself (to different subjects or to one and the same subject at different times) in different manners - as when being red manifests itself as reddish to someone yet as bluish to someone else, or to that very someone at a different time - but also different worldly properties may manifest themselves in one and the same manner - as when one has a uniform chromatic experience in which what actually are differently colored parts of a pointillist picture are manifested. Indeed, while manners of manifestation are the subjective ways in which worldly properties manifest themselves in the subjects' experiences (hence they are properties of the experience itself), modes of presentation are the objective ways in which worldly properties are given: objective looks, as some would say. ${ }^{15}$ In the typical example, sticks immersed in water have an objective "bent" look that manifests itself differently to those who perceive it.

Now, such manners of manifestation display themselves to the subject undergoing the relevant experience. As we said before, this amounts to saying that these manners are precisely properties of the experience that differ from the worldly properties they present; again, they are phenomenal properties, i.e., properties determining the phenomenal character of such an experience. For instance, the property of redness*, i.e., the property of phenomenally looking red, is one of the manners in which the property of being red manifests itself to the subject entertaining an experience of red. ${ }^{16}$ Thus, the

\footnotetext{
${ }^{14}$ As many differently stressed; cf. Block 1996, Loar 2003, Nida-Rümelin 2011, Siewert 2004.

${ }^{15}$ Cf., e.g., Martin 2010.

${ }^{16}$ As Frey (2013, p. 74) holds, one can entertain such manners of manifestation even if there is not only no actual instantiation of the worldly property they manifest,
} 
former property is what qualifies that subject's experience of the latter property; hence, it is a phenomenal property of that experience. ${ }^{17}$ As such, there is no reason why these properties have to be wide. For, even if the properties the experiences grasp are, qua worldly properties, wide, the manners in which those properties manifest themselves to the subject experiencing them may not be such. So all in all, let us suppose that transparency, meant as the claim that some properties apparently of an experience are worldly properties of that experience, holds. However, if our above remarks are right, this does not show that phenomenal properties are wide.

A fan of transparency may reply that what transparency shows is that there are no properties of the experience; for what introspection reveals are only worldly properties the experience grasps. Yet even this reply is controversial if one draws a distinction between strong and weak transparency and claims that manners of manifestation are not strongly transparent, but weakly transparent (where weak transparency is characterized as a sort of peripheral introspective availability), in the sense that it is not impossible in principle to be introspectively aware of them. ${ }^{18}$ So, although transparency reveals that properties apparently of the experience are worldly properties, it does not entail that all those properties are such. There may still be some residual properties that still belong to the experience, so that introspection may also focus on them. ${ }^{19}$ These properties are the manners in which the worldly properties that experience grasps manifest themselves within the experience itself. Indeed, we can introspectively focus on such manners, as weak transparency predicts. Thus, transparency does not force us to say that the phenomenal

as when one hallucinates something, but also no such property at all, as may be the case with Ganzfeld experiences. In such cases, to put it in Block's 1996 terms, one would entertain no mental paint, but rather a mental latex (as is probably the case with all interoceptive sensations; cf. Voltolini 2013). For the purposes of the present paper, however, we remain neutral on this issue.

${ }^{17}$ Clearly enough, in being properties of the experience itself, they are not sensedata, conceived as intermediary mind-dependent objects between the experience itself and the worldly object the experience puts us in contact with. Indeed, as Smith (2002, chap. 4) has clearly shown, there is no need for such objects in order to explain why an experience is a presentation of worldly properties or, in our way of putting things, such properties manifest themselves in the experience.

${ }^{18}$ For this distinction, cf. Kind 2003.

${ }^{19}$ Curiously enough, this point was anticipated by the original sustainer of the claim that experience is transparent, G.E. Moore: "When we try to introspect the sensation of blue, all we can see is the blue: the other element is as if it were diaphanous. Yet it can be distinguished if we look attentively enough, and if we know that there is something to look for." (1922, p. 25). 
character of an experience is exhausted by the worldly properties the experience grasps. By way of an example, introspection primarily reveals that an absent-minded subject grasps the same worldly property - say, the blueness of the sky - she grasps when she is concentrating on seeing the same object - the sky. Yet this does not mean that the subject grasps the same property in the same manner both times, as introspection itself may secondarily reveal by now focusing on the experiences themselves rather than on the worldly property such experiences grasp.

\section{Against the Error Argument}

Once we have shown that the properties of experience can be understood as manners of manifestation of worldly properties, a further phenomenal externalist argument can be dispensed with. For Tye (2000), if there were properties of experience that displayed themselves to the subject and yet did not coincide with worldly properties, then our ordinary perceptual experience would be imbued with massive error. For, one may suspect, we would be held captive by a veil of illusions that would prevent us from reaching the external reality. ${ }^{20}$

We can easily reply to this short argument by appealing to the idea we introduced in the previous section that the properties of experience can be understood as manners of manifestation of worldly properties that experience grasps (the properties that for intentionalists are represented by the experience). If properties of experience are manners through which worldly properties manifest themselves to the experience's bearer, the problem that Tye raises vanishes. No entertainment of an experience property amounts to a misrepresentation of the corresponding worldly property, for such an entertaining rather is the mode for the latter property to reveal itself to the experience's bearer. However differently reddish are our experiences of red, being red is still the worldly property of those experiences that manifests itself to us through those reddish manners. Hence, no such experience misrepresents it.

\section{Against the Individuation Argument}

To be sure, the phenomenal externalist may concede that there are phenomenal properties that are narrowly individuated for they are not constituted by worldly properties. However, this does not mean that

${ }^{20}$ Cf. Tye 2000, p. 46. 
all phenomenal properties are so individuated. Phenomenal disjunctivism is the form of PE that articulates this idea, so as to ground the kind of phenomenal externalist argument we are going to consider.

According to phenomenal disjunctivism, a genuine perception and an indistinguishable hallucination belong to metaphysically different kinds of mental states, for they share no fundamental kind. As Martin concedes ${ }^{21}$ one may even interpret such an indistinguishability as a phenomenal indistinguishability (PInd), hence as a sort of phenomenal identity between such experiences consisting in the identity of some of their phenomenal properties, namely the properties constituting their phenomenal character. Yet this does not make such experiences mental states of the same kind, for they are still phenomenally different, in a way that makes them also metaphysically different.

To begin with, according to Martin's phenomenal disjunctivism, even genuine and yet phenomenally indistinguishable perceptions of different objects - say, a perception of an apple and a perception of another identically looking apple - are still essentially phenomenally different. For, although they share the same phenomenal character, they do not share what Martin calls their phenomenal nature. Indeed, phenomenal nature is constitutively individuated by the object a perceptual state is about. As a result, a difference in such objects yields a difference in such natures. In other terms, such states are still essentially phenomenally different for they present different things that constitute such natures. Hence there are at least some phenomenal properties, the specific properties of presenting objects that genuine perceptions have, which are individuated widely.

Besides, if the above is the case, then not only a genuine perception and a phenomenally indistinguishable hallucination are essentially phenomenally different, but also and more radically, they are metaphysically different in kind. More precisely, to start with, since the first presents an object (say, an apple) that constitutes its phenomenal nature while the second presents nothing at all, unlike the former the latter utterly has no phenomenal nature. Moreover, the former (the genuine perception) is even different in metaphysical kind from the latter (the hallucinatory experience), for unlike the latter it is constitutively shaped by an object. ${ }^{22}$ So once again, PE

${ }^{21}$ Cf. Martin 2002, pp. 184-185.

${ }^{22}$ Fish (2009, p. 11) allows for a distinction between phenomenal character and presentational character: the latter is made by worldly properties the former is acquainted with. Yet for him Martin's difference between phenomenal character and phenomenal nature does not hold. Since for him hallucinations have no presenta- 
remains unscathed: there is wide phenomenology, for the phenomenal nature of an experience is individuated in extrinsic terms. In a nutshell, here it is how the individuation argument we can draw from Martin (2002) basically runs:

(1) Phenomenally indistinguishable states may well share their phenomenal character even if they do not share their phenomenal nature.

(2) Insofar as such states present to the subject's mind different objects that constitute their phenomenal natures, they differ in such natures.

(3) Hence, a phenomenally indistinguishable state that presents no object has no phenomenal nature.

(4) Therefore, phenomenal nature is wide. ${ }^{23}$

In our view, the most troublesome premise of this argument is (2). This is the premise that we shall attack in our critical discussion of this externalist argument. Before doing that, however, we want to stress that we take (3) to be problematic as well, even though we will not focus our main criticism on it. Let us thus start with (3).

tional character (for they involve no worldly properties), they have no phenomenal character either, insofar as the latter is just acquaintance with the former. For him, hallucinations are simply experiences that have the same cognitive effects as the corresponding veridical perceptions, which are instead endowed with a phenomenal character: the first of these cognitive effects is the fact that hallucinations are (erroneously) believed by their bearers to be such perceptions. To be sure, we have followed Martin in allowing a phenomenal character to hallucination, for on the basis of our rejection of the transparency argument in favor of PE we have already allowed experiences in general, hence hallucinations as well, to have a phenomenal character that is not determined by worldly properties, the properties that for Fish in the case of a perception would constitute its presentational character. However, we also think that Fish's conception of a hallucination hardly provides sufficient conditions in order for a mental state to be a hallucination. Consider my zombie twin's present perception. Such a perception allegedly has the same cognitive effects as my conscious counterpart: the zombie inter alia believes it to be a perception precisely endowed with the phenomenal character of such a state. Yet it has no phenomenal character precisely because it is an unconscious perception. Obviously enough, however, it is no hallucination, not even the hallucination I would entertain instead of my present perception if things just went wrong in the external world; indeed, it relates my zombie twin with an object existing in her environment. Yet according to Fish, it would turn out to be a hallucination, precisely because it shares the cognitive effects of my present perception even if it has no phenomenal character.

${ }^{23}$ Cf. Martin 2002, pp. 187-188, 194-196, 210. 
Can something that has just phenomenal character fail to have a phenomenal nature, i.e., a phenomenally determined essence, as (3) states? This would mean that purely phenomenal states, i.e., phenomenal states that have no intentionality, have no phenomenal nature. Moreover, since as we have seen for Martin's disjunctivism it is the phenomenal nature of phenomenal states that determines their metaphysical nature, it would follow that purely phenomenal states would not have the same kind of metaphysical nature as phenomenal intentional states, i.e., a phenomenally determined metaphysical nature. Yet it is also very problematic to hold that the essence of those states is not phenomenally determined. As Kripke (1980) famously maintained, pain is essentially painful. To rule out such cases, one would have to assume intentionalism: phenomenal states like pain are only apparently purely phenomenal, for their phenomenal properties are identical with, or at least supervene on, some of their represented properties. Yet, intentionalism about interoceptive sensations is known to be problematic. ${ }^{24}$ Independently of this, moreover, as we said at the beginning, this assumption (together with the further assumption that intentionalism is wide) proves $\mathrm{PE}$ in an uninteresting way, so this is not an argumentative path worth pursuing.

To be sure, Martin might remark that the phenomenological claim and the metaphysical claim are distinct ones ${ }^{25}$ hence, one may still ascribe a metaphysical nature to phenomenal states that fail to have a phenomenal nature. This would block the second problem. As to the first problem, Martin would probably reply that hallucination has just phenomenal character but no phenomenal nature, for it is phenomenally parasitic on genuine perception -it is as if it presented objects. ${ }^{26}$

Yet we wonder whether one may legitimately provide such a fictionalist treatment of hallucination. ${ }^{27}$ In actual fact, unlike a makebelieve perception, a hallucination is not a modification of a genuine perception.

First of all, as many fictionalists may be well disposed to say, ${ }^{28}$ a make-believe perception is a genuine perception yet in a different context, namely, a certain make-believe world. Yet entertaining a

${ }^{24}$ Cf. Block 1996; see also Voltolini 2013.

${ }^{25}$ As Martin (2002, p. 198) indeed says.

${ }^{26}$ Cf. Martin 2006, pp. 359, 366, 393-395, 404. See also Nudds 2013.

${ }^{27}$ Pace Evans 1982.

${ }^{28}$ By following the idea that pretense involves context-shift; cf. Recanati 2000, pp. 232, 257; Voltolini 2006. 
hallucination is not like entertaining a perception in a make-believe world. For it is actually entertaining something.

Moreover, suppose even that one does not endorse this contextshift approach to make-believe, by holding that a make-believe perception is a sort of actual imagination. Yet it remains that a hallucination is not such an imagination. For, unlike the latter, the former is phenomenally as vivid as the corresponding genuine perception would be. For, otherwise, it would not be able to deceive its bearer. As we will immediately see, unlike an imagination and like a corresponding genuine perception, a hallucination is such that its bearer entertains a feeling of presence as to what she hallucinates.

Be that as it may, the real trouble as we have anticipated is with premise (2) of Martin's above argument. For (3) actually follows from (2), yet (2) is problematic on its own. There are various ways - at least, four in our view - in which one may interpret the locution "being present to the mind", i.e., by appealing either to (i) presentness in content, or to (ii) presentness in mode, or even to (iii) feeling of particularity, or finally to (iv) vividness. Yet none of these ways supports (2). Or so we claim.

To begin with, something may be present to the mind in the sense (i) that it is ascribed the property of being in front of the subject of the relevant mental state; being present to the mind in this sense, being out there, is thus a feature of the content of that state, a represented property. Now, this sense of being present to the mind may enable a subject to tell her genuine perceptions from her thoughts, or even from her imaginations: in none of the latter cases the object of such states is ascribed the property of out-thereness, to give it a vivid name. Yet this sense does not enable a subject to tell one of her genuine perceptions from another one, let alone a phenomenally indistinguishable one. For in both cases one experiences something to be out there. ${ }^{29}$ Thus, the sense of being present to the mind captured by (i) does not justify (2), for it is unsuited to make any difference in the states' phenomenal nature.

Moreover, one may say that something is present to the mind in the sense (ii) that it is felt to be such. In such a case, that something is present to the mind qualifies not the content, but the mode, of the relevant mental state, that is, what makes such a state either an experience of a certain kind rather than of another one or a thought

\footnotetext{
${ }^{29}$ This sense does not even enable one to tell her genuine perception from a phenomenally indistinguishable hallucination. For even in the latter case something is ascribed - admittedly, erroneously - out-thereness.
} 
of a different kind. ${ }^{30}$ In other terms, the state is colored by the feeling of presence regarding the object it is really or purportedly directed to. Once again, this feeling may tell a genuine perception from a thought and even from an imagination: when we think of or we imagine something, we enjoy no such feeling of presence. ${ }^{31}$ Yet again, not only does this feeling not tell a genuine perception from a phenomenally indistinguishable hallucination, but also from another such indistinguishable perception. For all such experiences are so colored. So again, this sense of presentness does not justify (2).

Furthermore, one may say that something is present to the mind in the sense (iii) that it is felt as being about a particular individual. In this respect, one may say, it is as if a particular object presentified itself to someone. ${ }^{32}$ Once again, presentness to the mind as a feeling of phenomenal particularity qualifies the mode of an experience by telling it from a corresponding thought: thoughts are at most accompanied by a belief in their being about a particular individual, not by a feeling of particularity. Yet again, even leaving the case of imagination aside, phenomenal particularity not only does not tell a genuine perception from a phenomenally indistinguishable hallucination, but also from another such genuine yet phenomenally indistinguishable perception: all such experiences are felt as being about something. In actual fact, this feeling of particularity is general, hence non-relational. ${ }^{33}$ Thus, not even the sense of presentness to the mind captured by (iii) justifies (2).

Finally, one may say that something is present to the mind in the sense (iv) that it manifests itself to the relevant state's bearer in a vivid way. This sense of being present to the mind, vividness, mobilizes the aforementioned manners of manifestation of worldly properties. Indeed, the worldly properties an experience grasps manifest themselves to that experience's bearer in a manner that, by substantially qualifying that experience, confers vividness upon it. ${ }^{34}$ By so doing, vividness tells genuine perceptions from the corresponding thoughts (as well as from imaginations as we said before): unlike

${ }^{30}$ Nida-Rümelin (2011, p. 353) claims that this sense of being present to the mind indeed qualifies the phenomenal character of one's experience.

${ }^{31}$ Cf. on this, e.g., Dokic 2012.

${ }^{32}$ For such a sense, cf. Montague 2011, Schellenberg 2010. In the same vein, Loar 2003 speaks of an experience of directedness.

${ }^{33}$ Cf. Montague 2011, Schellenberg 2010, Sacchi 2013. Along similar lines, Pautz 2007 says that a perception exhibits a non-relational phenomenology.

${ }^{34}$ See also Frey 2013. 
a perception of an object, a thought about the same object is somehow empty. ${ }^{35}$ Yet again, not only does vividness not tell a genuine perception from a phenomenally indistinguishable hallucination, but also from another such genuine yet phenomenally indistinguishable perception: all such experiences are vivid insofar as the same worldly properties manifest themselves in the same way to a subject. Once again, therefore, not even the sense of being present to the mind captured by (iv) justifies (2).

On behalf of the phenomenal disjunctivist à la Martin, one might reply that there is a further sense of presentness not yet explored. In a phenomenal state, aboutness itself has a phenomenal import: for such a state to be about something is for its bearer to be aware of something, hence aboutness is a presentation of that very something in some further sense. ${ }^{36}$ Now, such an aboutness is relational. Hence, hallucination does not possess it and is thereby phenomenally different from a genuine yet phenomenally indistinguishable perception of something. Moreover, being aware of a certain object is different from being aware of another object. Thus, even genuine yet phenomenally indistinguishable perceptions of different objects are phenomenally different. So finally, (2) in the above argument is perfectly justified. To put the argument in a suitable form:

(a) There is a further sense in which a genuine perception presents its object: by letting its bearer being aware of it (something a hallucination cannot have, for unlike a genuine perception a hallucination is non-relational).

(b) An experiencer's being aware of an object is relevant for the phenomenal nature of her experience (in particular, of her genuine perception).

(c) An experiencer's being aware of a certain object (in a certain genuine perception) is different from that experiencer's being aware of another object (even in another, yet phenomenally indistinguishable, such perception).

${ }^{35}$ As Husserl 1970 originally stressed in talking about the fullness of perception.

${ }^{36}$ This way of phenomenally coloring the aboutness of a phenomenal state has certainly some affinities with the phenomenal characterization of intentionality, namely with the thesis that phenomenal states have intentionality in virtue of their having a certain phenomenal character (cf. Kriegel 2011, p. 44). Yet since the phenomenal intentionality thesis is normally combined with the idea that intentionality is narrow because phenomenal character is such, a phenomenal externalist obviously cannot appeal to that thesis. 
(d) Hence, such states differ in their phenomenal nature -i.e. (2). ${ }^{37}$

In the above reply, (c) is indisputable, if being aware of is relational. To be sure, one may wonder whether this relationality really makes a hallucination phenomenally different from a genuine perception, as (a) holds. For one may wonder whether hallucination is really nonrelational, since it is about an object that does not exist. ${ }^{38}$

Yet let us put this Meinong-like worry aside. The real trouble is with (b). To be sure, some relational properties may be metaphysically essential, hence they may provide different metaphysical essences for the entities that respectively possess them (cf. e.g. the properties of being the offspring of gametes $G$ vs. being the offspring of gametes $G^{*}$ ). Yet different phenomenal relational properties are not eo ipso phenomenally essential, so as to supply the entities that respectively possess them with different phenomenal natures. For, to expand on this point, it may be the case that an experiencer's being aware of something is relevant for the phenomenal nature of her experience. Yet it is not being aware of a particular something that is so relevant. Phenomenal states that mobilize such an awareness may be related to different particulars, but such distinct relata make no phenomenally essential difference. In other terms, the relational properties of being aware of a certain particular and of being aware of another particular are surely both different (because of their different relata) and phenomenal (because of their being instances of the phenomenal relation of being aware of), but they are not phenomenally different. ${ }^{39}$

To better see this point, consider pain localization. One can feel a pain in the left toe and then feel again a pain in the right toe. To be localized is definitely relevant for the phenomenal nature of a pain - a non-localized pain, if there were any, would surely feel differently - but to be localized here rather than there is not eo ipso relevant for that nature. Even if for argument's sake one rules out

${ }^{37}$ For such a reply, cf. Martin 2002, p. 187.

${ }^{38}$ As, e.g., Harman 1990 seems to suggest. For the idea that one must take seriously the fact that a hallucination is about a (non-existent) object, cf. also Smith 2002, chap. 9.

${ }^{39}$ Moore himself insisted on the fact that awareness is a common feature of experiences that put their experiencers in touch with different items (cf. again Moore 1922, p. 25). Probably Fish (2009) would agree with Moore on this. For in saying that phenomenal character is acquaintance with presentational character (i.e., certain worldly properties), he would probably also be disposed to say that being acquainted with a certain presentational character is relationally different yet phenomenally identical with being acquainted with another presentational character. 
"hallucinatory" pains in phantom limbs having no real localization, still two pains that differ just by their localization feel the same, even if they are respectively localized in different places. This would certainly be the case if what is at stake were just one and the same numerically identical pain; namely, a migrant pain localized now here, now there. Its present localization notwithstanding, that pain would still feel the same. Yet having to do with numerically different pains, as in the above case, makes no difference for this purpose.

But if we so qualify (b), then (d), which amounts to (2), does not follow from (a)-(c). Phenomenally indistinguishable states are also identical as to their phenomenal nature, regardless of which objects they are about, hence of what their subjects are aware of.

At this point, our phenomenal disjunctivist has just one last straight line of defense: distinguishing as before between phenomenal character and phenomenal nature simply presupposes that there is an inaccessible phenomenology.

Now, if "inaccessible" here means "epistemically inaccessible", we can agree: as we have already seen, phenomenal awareness may well be opaque to report awareness. For example, in this second sense of "awareness" we will never be aware of the fact that two pairs of slightly different shades, i.e., the $A$ and $B$ pair and the $B$ and $C$ one, are phenomenally distinct, if the only thing we can be aware of, in this sense of "awareness", is that $A$ is phenomenally distinct from $C$. Yet suppose that "inaccessible" here means "phenomenally inaccessible", i.e., it introduces a phenomenology that is opaque even to phenomenal awareness, as the disjunctivist in question would like. Then as to the burden of the proof, it is on such a disjunctivist to show in which sense what she calls phenomenology is a phenomenology. Behind phenomenally conscious mental states there are only sub-personal unconscious mental states, namely states that cannot have any phenomenology whatsoever. ${ }^{40}$

\footnotetext{
${ }^{40}$ To be sure, it is possible that unconscious mental states are still to be divided between subjective mental states and non-subjective mental states, if subjectivity can be defined, as Shani (2007) suggests, in terms of organicity. Yet this unconscious subjectivity is no route to a phenomenally inaccessible phenomenology. Pitt (2011, pp. 144 and nn. 5-6) is sympathetic to the idea that there may be phenomenal unconscious states. Yet if by "phenomenal unconscious states" he means "phenomenal states lacking phenomenal awareness", he has to explain in which sense such states are phenomenal. One may well accept that phenomenal awareness comes in different phenomenal varieties: sensuous, non-sensuous, etc. Yet this variety provides no support for claiming that phenomenal awareness is not necessary for phenomenality (or, which is the same, that phenomenality is not sufficient for phenomenal awareness). In point of fact, there may well be phenomenal differences between, e.g., achromats
} 
Before concluding this section, it is fair to say that when Martin originally reflected on these matters (1997), he had implicitly provided another argument in favor of his disjunctively based phenomenal externalism. Suitably reconstructed, this is the argument:

(1) Objects indistinguishable in their lookings are still discriminable: one can tell any of them from the other surrounding objects.

(2) Such a discrimination has a phenomenal import.

(3) Hence, to tell one object from its environment is phenomenally different from telling its phenomenal counterpart from its own environment (possibly, a Twin-Earth environment). ${ }^{41}$

Yet the derivation of (3) from (2) is problematic. Clearly enough, one can phenomenally discriminate within a genuine perception a certain object from its contextual look-a-likes, by referring to the perceived location of that object. Yet one cannot phenomenally discriminate across genuine perceptions a certain object of one perception from the object of another perception, if those perceptions of those objects share all their phenomenal properties. For the experienced location of the objects respectively perceived is just a further such property that the two genuine perceptions in question share. Granted, the first perception can be singled out from the second perception. Yet this is just a numerical distinction. If it were a qualitative distinction, some of the phenomenal properties of those perceptions should be different. Yet this option is ex hypothesi ruled out, for the two perceptions in question share their phenomenal character.

\section{Against the Weirdness Argument}

There is, however, a final argument one may launch in favor of the interpretation of phenomenal properties in general as extrinsic properties, i.e., as individuated in terms of the worldly properties an experience is in relation with. The argument is centered on the idea that, if we claimed that phenomenal properties are intrinsic, hence monadic aka non-relational, properties of our experiences, we would

and normally sighted people. Yet this fact provides no support for saying that there are phenomenal differences between, e.g., blindsighters and sighters in general, in the sense that the former but not the latter would entertain phenomenal states lacking phenomenal awareness. For the phenomenal difference between achromats and normally sighted people is just a difference in forms of phenomenal awareness.

${ }^{41}$ Cf. Martin 1997, pp. 92-94. 
be forced to say that such properties are metaphysically weird, that is, intrinsic properties whose nature is so obscure that it would be better to dispense with them altogether: namely, some sort of immaterial, free-floating ghostly properties. On the contrary, PE has not such a problem, for it metaphysically equates phenomenal properties with worldly properties. Here is how the weirdness argument in fact runs:

(1) If phenomenal properties were not individuated in extrinsic terms, as being constituted by worldly properties, unless they were individuated functionally they would be weird properties (i.e., intrinsic immaterial free-floating ghostly properties).

(2) Phenomenal properties are plausibly not functional, but not actually weird.

(3) Therefore, phenomenal properties are individuated in extrinsic terms. $^{42}$

We can agree on premise (2); in particular, its first conjunct relies on well-known traditional arguments against functionalist accounts of phenomenal properties (typically, absent qualia or inverted qualia arguments). ${ }^{43}$ Yet (1) in the above argument is not warranted. Granted, intrinsic non-functional phenomenal properties would be weird if they were properties of weird entities, such as sense-data may be. ${ }^{44}$ Yet there may well be other metaphysical accounts of such properties qua properties of our experiences that make them not weird at all; for instance, a physicalist account of them. ${ }^{45}$ As a matter of fact, the failure of a functionalist account of phenomenal properties does not entail the failure of a physicalist account. So it is not true that, as the above argument states, if we abandon PE there is no plausible internalist metaphysical account of phenomenal properties. Thus again, we have found no convincing support for PE.

Clearly enough, a physicalist account of phenomenal properties raises well-known problems, such as that presented by the antimaterialist versions of the above traditional arguments, or even the problem famously raised by Jackson's (1986) Knowledge Argument. Yet, it may well be the case that such problems are circumvented,

${ }^{42}$ For such an argument, cf. Lycan 2001.

${ }^{43}$ Independently of these traditional arguments in support of (2), one may also take note of Kriegel's $(2009,2011)$ claim that phenomenal properties cannot be dispositional properties, as functional properties instead are.

${ }^{44}$ As Lycan (2001) himself suggests.

${ }^{45}$ As Block (1996) himself recommends. 
as may be suggested by the fact we originally stressed, i.e., that neurosciences seem to go hand in hand with the intuition, either doxastically or phenomenally based, that phenomenal properties are intrinsic. Granted, how to positively show that phenomenal properties are physical is a complex issue. Unfortunately, to deal with it is a topic for another paper.

\section{Conclusion}

All in all, we have found no cogent argument in favor of PE. To be sure, we have provided no argument in favor of PI either. Yet, since as we said at the very beginning of this paper, PI has intuitions on its side that neuroscience shares, in the course of this paper we have seen no reason as to why, as the phenomenal externalist claims, we ought to abandon such intuitions, hence to dispense with PI. ${ }^{46}$

\section{REFERENCES}

Bayne, T. and M. Montague (eds.), 2011, Cognitive Phenomenology, Oxford University Press, Oxford.

Block, N., 1996, "Mental Paint and Mental Latex", Philosophical Issues, vol. 7, Perception, pp. 19-49.

Chalmers, D.J., 2004, "The Representational Character of Experience", in B. Leiter (ed.), The Future of Philosophy, Oxford University Press, Oxford, pp. 153-181.

Crane, T., 2001, Elements of Mind, Oxford University Press, Oxford.

Dokic, J., 2012, "Pictures in the Flesh: Presence and Appearance in Pictorial Experience", British Journal of Aesthetics, vol. 52, no. 4, pp. 391-405.

Dretske, F., 1995, Naturalizing the Mind, The MIT Press, Cambridge, Mass.

Evans, G., 1982, The Varieties of Reference, Oxford University Press, Oxford.

Farkas, K., 2006, "Indiscriminability and the Sameness of Appearance", Proceedings of the Aristotelian Society, vol. 106, pp. 207-227.

${ }^{46}$ This paper was first presented at the conference Phenomenality and Internalism, Ernst Mach Workshop II, Academic Conference Center, 24-25 June, 2013, Prague, and then in other seminars at the universities of Bergamo and Turin. We thank the participants for their useful questions. We are also indebted to two anonymous referees of Crítica for their comments and criticisms to a previous draft. Although this paper was conceived and discussed together, Elisabetta Sacchi is particularly responsible for sections 2, 4, and 6, while Alberto Voltolini is particularly responsible for sections 3 and 5 . 
Fish, W., 2009, Perception, Hallucination, and Illusion, Oxford University Press, Oxford.

Frey, C., 2013, "Phenomenal Presence", in U. Kriegel (ed.), Phenomenal Intentionality, Oxford University Press, Oxford, pp. 71-91.

Harman, G., 1990, “The Intrinsic Quality of Experience”, Philosophical Perspectives, vol. 4, pp. 31-52.

Husserl, E., 1970, Logical Investigations, trans. J.N. Findlay, Routledge and Kegan Paul, London.

Jackson, F., 1986, “What Mary Didn't Know", The Journal of Philosophy, vol. 83, no. 5, pp. 291-295.

Kind, A., 2003, "What's So Transparent about Transparency?", Philosophical Studies, vol. 115, no. 3, pp. 225-244.

Kriegel, U., 2011, The Sources of Intentionality, Oxford University Press, Oxford.

- 2009, Subjective Consciousness: A Self-Representational Theory, Oxford University Press, Oxford.

Kripke, S., 1980, Naming and Necessity, Blackwell, Oxford.

Loar, B., 2003, "Transparent Experience and the Availability of Qualia", in Q. Smith and A. Jokic (eds.), Consciousness, Oxford University Press, Oxford, pp. 77-96.

Lycan, W.G., 2001, “The Case for Phenomenal Externalism”, Philosophical Perspectives, vol. 15, pp. 17-35.

Martin, M.G.F., 2010, “What's in a Look?", in B. Nanay (ed.), Perceiving the World, Oxford University Press, Oxford, pp. 160-225.

—_, 2006, "On Being Alienated", in T.S. Gendler and J. Hawthorne (eds.), Perceptual Experience, Oxford University Press, Oxford, pp. 356410.

, 2004, "The Transparency of Experience", Mind and Language, vol. 17, no. 4, pp. 376-425.

, 2002, "Particular Thoughts and Singular Thought", in A. O'Hear (ed.), Logic, Thought, and Language, Cambridge University Press, Cambridge, pp. 173-214.

, 1997, "The Reality of Appearances", in M. Sainsbury (ed.), Thought and Ontology, Franco Angeli, Milan, pp. 81-106.

Montague, M., 2011, "The Phenomenology of Particularity", in Bayne and Montague 2011, pp. 121-140.

Moore, G.E., 1922, "The Refutation of Idealism", Philosophical Studies, Routledge and Kegan Paul, London, pp. 1-30.

Nida-Rümelin, M., 2011, "Phenomenal Presence and Perceptual Awareness: A Subjectivist Account of Perceptual Openness to the World", Philosophical Issues, vol. 21, The Epistemology of Perception, pp. 352-383.

Nudds, M., 2013, "Naïve Realism and Hallucinations", in F. MacPherson and D. Platchias (eds.), Hallucinations, The MIT Press, Cambridge, Mass., pp. 271-290. 
Pautz, A., 2007, "Intentionalism and Perceptual Presence", Philosophical Perspectives, vol. 21, no. 1, pp. 495-541.

Pitt, D., 2011, "Introspection, Phenomenality, and the Availability of Intentional Content", in Bayne and Montague 2011, pp. 141-173.

Raftopoulos, A., 2009, Cognition and Perception, The MIT Press, Cambridge, Mass.

Recanati, F., 2000, Oratio Obliqua, Oratio Recta, The MIT Press, Cambridge, Mass.

Sacchi E., 2013, "The Content and Phenomenology of Perceptual Experience", Phenomenology and Mind, vol. 4, pp. 187-210.

Schellenberg, S., 2010, "The Particularity and Phenomenology of Perceptual Experience", Philosophical Studies, vol. 149, no. 1, pp. 19-48.

Shani, I., 2007, "Consciousness and the First Person", Journal of Consciousness Studies, vol. 14, no. 12, pp. 57-91.

Siewert, C., 2004, "Is Experience Transparent?", Philosophical Studies, vol. 117, no. 1-2, pp. 15-41.

Smith, A.D., 2002, The Problem of Perception, Harvard University Press, Cambridge, Mass.

Tye, M., 2000, Consciousness, Color, and Content, The MIT Press, Cambridge, Mass.

of the Phenomenal Mind, The MIT Press, Cambridge, Mass.

Voltolini, A., 2013, "The Mark of the Mental", Phenomenology and Mind, vol. 4, pp. 124-136.

- 2006, "Fiction as a Base of Interpretation Contexts", Synthese, vol. 153, vol. 1, pp. 23-47.

Received: July 2, 2016; revised: March 5, 2017; accepted: April 4, 2017. 